REVIEWS OF DATASETS

Filipa Ribeiro da Silva

\title{
African Population Estimates, 1850-1960
}

Review of: African Population Estimates, 1850-1960

Author/Compiler: Patrick Manning

Repository: World-Historical Dataverse: http://www.dataverse.pitt.edu,

The Archive $>$ World Historical $>$ African Population;

Dataverse Network ID: hdl:1902.1/15281

Date of Posting: 09/04/2009

Size: $858 \mathrm{~KB}$

Volume 1, No. 1 (2013) | ISSN 2169-0812 (online)

DOI 10.5195/jwhi.2013.5 | http://jwhi.pitt.edu 
For the past several decades, scholars have struggled to estimate the size of African population during the pre-colonial and colonial eras due to the lack of reliable historical population counts for the continent and the problems of underestimation of colonial populations by European officials. Patrick Manning's "African Population Estimates" Database offers the academic community an important new set of projections of the African population for the period 1850-1960. With this dataset the author not only revises the previous estimates on African colonial population figures, including the calculations by Angus Maddison and others, but also reviews the estimates of African population sizes in the pre-colonial era. In addition, Manning introduces an innovative methodology into the study of African demographics, by using back-projection of population growth rates adjusted in time and space according to key historical phenomena and processes with potential effects on population behavior. This new methodology produces more accurate and reliable population estimates than earlier methods and is therefore paramount to overcoming the difficulties encountered until now by scholars aiming at estimating African population sizes and behavior.

Manning's dataset is made available to the user in Excel format, comprising a total of twenty sheets. A table of contents is displayed in the first sheet to guide the user through the materials available. This is followed by Appendix A, i.e. an introductory text to the dataset including a reflective and critical analysis of the method used and discussion of possible margins of error. In the following nineteen sheets users can access the detailed information compiled and calculated by Manning.

In each table, the author provides users with estimates at a country (territory), and regional level (West-, Central-, North East-, Southern-, East- and North Africa), as well as for sub-Saharan Africa and the entire continent. For certain territories (countries), Manning also offers the user quantitative information at a sub-regional level. This is for instance the case of Ghana for which territory the author provides detail data for the Akan, TVT (Trans-Volta Togoland) and Northern Gold Coast. Similar levels of information detail can also be found in the sets of data for Dahomey, Nigeria, Central African Republic, Cameroon, Equatorial Guinea, Congo-Kinshasa, Angola, Somalia, Sudan, Mozambique, Malawi, and Gambia.

The set of nineteen sheets starts with Table B1, which includes detailed information on African population sizes per territory for the years of 1950 and 1960 with annual growth rates for the intervening decade. Table B2, on the other hand, provides the user with a list of slave-importing regions in the continent; whereas Table B3 presents users with the default decennial growth rates per territory, slave-trade region and geographical area for the period 1850-1940.

In Tables B4 to B14, Manning shows all modifications done to the previous default decennial growth rates to weight the impact of several historical phenomena and processes taking place in the African continent during the period under study, such as: disorder caused by slave trade (Table B4), continental slave trade in the period 1850s1900s (Table B5), the impact of overseas slave trade between 1850 and 1900 (Table B6), population recovery in the post-slave-trade period (Table B7), and the impact of the establishment of colonial rule in the continent (Table B8).

Slave trade within the African continent and even overseas continued to be a common practice well into the colonial period, including the first half of the twentieth century; scholars from various fields also point to evidence that suggest the existence of modern forms of slavery in postcolonial Africa. In my view, it would be therefore relevant for the population projections to weight the impact of these phenomena in the period post-1900. On the recalculation of historical population growth rates it would also be important to ponder the impact of colonial forced 
labor regimes and policies of displacement of labor forces given not only the brutality of these colonial practices but also their direct bearing on individuals lives in terms of health conditions, fertility and their ability to reproduce. Here, it would also be of great interest, at least, in my point of view, to take into account the multiple forms of disorder taking place during colonial rule in Africa, in particular in the 1950s, which culminated in the independence of several Italian, French, British, and German colonies in the aftermath of the World War II (1939-1945), and the breakout of the independence movements and subsequent Colonial War (1961-1975) in the former Portuguese colonies.

In the new projections of African population for the period 1850s-1960s, Manning has also taken into consideration the impact of income growth on population growth rates (Table B9), as well as the weight of free migration movements (Table B10), and epidemics and famine (Table B11).

In regard to free migration (Table B10), most of the revisions done to the growth rates concern only territories in the West African region during the period 1860s-1930s, in particular the former French and British colonies. There is, however, evidence of migration of free people in Central, Northeast, East- Southern, and North Africa during the aforementioned period as well as during the era of colonial rule (despite the attempts on the part of the colonial authorities to prevent and stop mobility of population and labor force across borders in the first half of the twentieth century). Migration of free people remained a common feature of Africa demographics and population movements in the postcolonial period. As much as source materials will allow, movement and mobility of African free people should, in my view, be taken into account in the revision of population growth rates in a broader chronological and geographical frame.

In what concerns the impact of epidemics and famines (Table B11), these phenomena appear to have only been taken into account for a handful of countries, namely Liberia (1900s), Niger, Upper Volta, Mali (1920s-1940s), and Sudan (1920s). These are certainly territories located in the fringes of the Sahara Desert and as a consequence regularly affected by droughts, subsequent cycles of famine and outbreaks of several epidemic diseases. There are, however, various regions in Equatorial Africa, where tropical diseases are endemic still today and their impact in pre-colonial and nineteenth-century populations must have been greater due to lack of public sanitation and health care. On the other hand, tropical and sub-tropical regions in Africa are often also affected by seasonal floods with direct consequences in agricultural production and produce quality. The characteristics of types of eco-systems and disease environments certainly had impact on population growth rates at least until the mid-1900s and need to be, in my view, reflected more fully in the adjustments made to the population growth rates of a larger number of territories during a broader period.

All the aforementioned modifications to the population growth rates are compiled in Tables B12 to B14. The first Table shows the total revisions made to the default growth rates, the second offers users a comprehensive list of revised growth rates for each territory in every decade of the period 1850-1960, and the third summarizes the different types of historical phenomena taken into account in the revision of the population decennial growth rates of each territory during the period under study.

In the following set of tables listed under Table B15: Projected Population, the user can access the final results of the complex calculations through the method described earlier. This set includes three tables with mid-, high- and low-level population projections. These three tables cover all African territories for the period 1850-1950, as well as the main African regions, sub-Saharan Africa, and the entire continent. 
Overall, the new projections by Manning offer users important new insights into the figures and behavior of African populations. Population sizes are estimated to have been twenty-five and fifty per cent higher in the precolonial and colonial periods, than previous calculations suggested. The demographic transition in African population appears to have taken place between the 1900s and 1950s, with the greatest population growth being attained in the subsequent period, 1950-2000. Manning's evidence also suggests that growth rates are declining slowly during the same period. A lengthy discussion of the contribution of Manning's database to the topic can be found in "African Population: Projections, 1850-1960" in The Demographics of Empire. The Colonial Order and the Creation of Knowledge in Africa, edited by Karl Ittmann, Dennis D. Cordell, and Gregory H. Maddox (Athens, Ohio: Ohio University Press, 2010).

As mentioned in the introduction, Manning's database still includes projections of pre-colonial African populations. These are summarized in Table B18, where the user can access not only the estimated population sizes per slave-trade regions for three main cross-sections, i.e. 1850, 1950 and 2000, but also the proportional population size of each region in relation to the total population of the continent. Comparisons between the three aforementioned cross-sections also show the areas where population sizes increased and decreased proportionally to the entire continent in the first one hundred years and the last fifty years.

To assess the quality of his back-projections of African population for the period 1850-1960, Manning used Indian population growth rates for provinces and states in the decennia of 1871-1961 as comparative proxies. These are presented in the final Table of the dataset (B19). Indian growth rates were chosen by the author for comparative purposes because these refer to the behavior of populations living in tropical ecological and disease environments identical to the ones African population would have been exposed to. However, population behavior over time is not only affected by environmental aspects but also by changes in the demographic regimes induced by institutions either private and/or public. How comparable would the Indian subcontinent and Africa be at this level? Would Southeast Asian territories be a more suitable comparable proxy, as the effective occupation of these territories by European colonial powers and the impact of establishment of colonial rule and policies started to be felt around the same period as in Africa?

In brief, the new figures presented by Patrick Manning are in themselves a major contribution to the scientific community, but the major impact of this impressive work rests, in my opinion, in Manning's skill at opening new avenues for research and discussion with the inventive, innovative and reliable method underlying these fresh results, and more importantly his efforts to bring the topic of African demography to the attention of scholars and the broad public.

(cc) EY Articles in this journal are licensed under a Creative Commons Attribution 3.0 United States License.

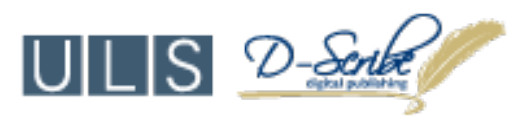


This journal is published by the University Library System of the University of Pittsburgh as part of its D-Scribe Digital Publishing Program and is cosponsored by the University of Pittsburgh Press. 